\title{
Factors affecting outcome of decompressive hemicraniectomy in malignant middle cerebral artery infarction
}

\author{
Sagar Koirala $M C h^{1}$ iD, Shreeram Bhandari $M B B S^{2}$ iD, Subash Lohani $M C h^{3}$ iD \\ 1,2,3 Department of Neurosurgery, Upendra Devkota Memorial National Institute of Neurological and Allied Sciences, \\ Bansbari, Kathmandu, Nepal
}

Date of submission: $14^{\text {th }}$ May 2021

Date of acceptance: $16^{\text {th }}$ August 2021

Date of publication: $1^{\text {st }}$ September 2021

\section{Abstract}

Introduction: Decompressive Hemicraniectomy (DHC) is a standard surgical management of malignant MCA (MMCA) infarction. This study was conducted to review the outcome of surgery and to find out factors associated with favorable outcomes at a tertiary level neurosurgery referral centre.

Methods and Materials: This is a retrospective study conducted over a period of three years from 2017 to 2019. Patient charts were reviewed for variable like age, sex, timing of surgery, GCS at presentation, length of ventilation, length of ICU admission and length of hospital stay. Primary outcome measure was GOSE: favorable $(<=4)$ and unfavorable $(>=5)$. SPSS version 23 was used for analysis.

Results: A total of 28 patients underwent DHC out of which 21 patients were available for analysis. Mean age of patients was 58.62 years. Mean GCS on arrival was 11.86. Mean interval duration between event and surgery was 51.88 hours. Mean duration of ventilation was 4.43 days. Mean length of ICU stay was 5.95 days. Mean hospital stay was 22.33 days. Mean GOSE was 2. Mean age was significantly lower in patients with favorable GOSE. Early surgery had better mean GOSE which was not significant statistically.

Conclusion: Patients with age less than 50 years have favorable GOSE despite MMCA infarction if decompressive hemicraniectomy is performed to accommodate brain swelling. Early surgery at presentation rather than waiting for deterioration might improve the outcome.

Key words: Decompressive hemicraniectomy, Malignant middle cerebral artery infarction.

\section{Introduction}

$\mathrm{M}$ alignant MCA (MMCA) infarction is a common indication for emergency decompressive hemicraniectomy (DHC) in neurosurgery. Its importance

Access this article online
Website: https://www.nepjol.info/index.php/NJN
DOI: https://doi.org/10.3126/njn.v18i3.37109
HOW TO CITE
Koirala S, Bhandari S, Lohani S. Factors affecting outcome of
decompressive hemicraniectomy in malignant middle cerebral
artery infarction. NJNS. 2021;18(3):35-8.

Address for correspondence:

Dr. Sagar Koirala

Upendra Devkota Memorial National Institute of Neurological and Allied Sciences,

Bansbari, Kathmandu, Nepal.

E-mail: sagarkoirala85@gmail.com

Phone: +9779851044286

Copyright (C) 2021 Nepalese Society of Neurosurgeons (NESON)

ISSN: 1813-1948 (Print), 1813-1956 (Online) has already been established by multiple trials like American HeADDFIRST, French DECIMAL, German DESTINY and Dutch HAMLET. ${ }^{1,2,3,4}$ We wanted to study factors that might be associated with favorable outcome in patients who underwent $\mathrm{DHC}$ at a tertiary level neurosurgery referral centre.

\section{Methods and Materials}

This is a retrospective study conducted over a period of three years from 2017 to 2019 at Upendra Devkota Memorial National Institute of Neurological and Allied Sciences. Patients who underwent DHC for MMCA infarction were enrolled for the study. A frontotemporoparietal decompressive hemicraniectomy of size at least $14 \mathrm{~cm}$ in greatest dimension with lax duroplasty with pericranial graft was done in these patients. Patient's records were reviewed for variables like age, sex, timing of surgery, GCS at presentation, side of decompression, length of ventilation, length of ICU admission and length of hospital stay. Patients' outcome measurement was done by Glasgow Outcome Scale-Extended (GOSE) (Table 1), assessed over the phone after a minimum of six months after discharge. 


\section{Koirala et al}

GOSE was dichotomized as favorable and unfavorable depending on whether the GOSE was five or more and four or less respectively. Date was analyzed by using SPSS version 23. T-test and Fisher exact test were used according to the type of data.

\section{Results}

There were a total of 28 patients who underwent DHC for MMCA infarction over the period of three years out of which only 21 patients were reachable by phone for GOSE assessment and thus were included in the analysis. Mean age of patients was 58.62 years (range 29 - 75). More than $70 \%$ of these patients were male ( 15 out of 21 ). Mean GCS on arrival was 11.86 (range $7-15$ ). Mean interval duration between event and surgery was 51.88 hours (range 4-312). Mean duration of ventilation was 4.43 days (range 1 to
14). Mean length of ICU stay was 5.95 days (range 2 17). Mean hospital stay was 22.33 days (range 2 - 82). Mean GOSE was 2 (range 0-5). Mortality despite DHC was about $50 \%$ (11 out of 21$)$.

Mean age was significantly lower in patients with favorable GOSE. Also, when age was dichotomized at 50 years, patients under 50 years had favorable outcomes which were statistically significant. There was no statistically significant difference found among duration of ventilation, length of ICU stay and hospital stay. Early surgery had better mean GOSE despite being insignificant statistically. Patients did better if they were operated on arrival rather than waiting for deterioration to intervene. (Table 2 and 3)

On comparing the side of malignant infarction decompressed for outcome, no significant difference was found whether the side was left or right as shown in table 4.

\begin{tabular}{|c|l|l|}
\hline Score & Definition & Interpretation \\
\hline 1 & Dead & Dead \\
\hline 2 & Vegetative State & Absence of awareness of self and environment \\
\hline 3 & Lower severe disability: & Needs full assistance in activities of daily living (ADL) \\
\hline 4 & Upper severe disability & Needs partial assistance in ADL \\
\hline 5 & Lower moderate disability & Independent but cannot resume school/work/social activities \\
\hline 6 & Upper moderate disability & Some disability but can partially resume school/work/social activities \\
\hline 7 & Lower good recovery & Minor deficits that affects daily life \\
\hline 8 & Upper good recovery & Fully recovered \\
\hline
\end{tabular}

Table 1: Glasgow Outcome Scale- Extended.

\begin{tabular}{l|c|c|c}
\hline Variable & Unfavorable $(\mathbf{N}=\mathbf{1 6})$ & Favorable $(\mathbf{N}=\mathbf{5})$ & P value \\
\hline Mean age (years) & 62.5 & 46 & 0.002 \\
\hline Mean GCS & 11.75 & 12.20 & 0.756 \\
\hline Mean interval of event to surgery (hours) & 59.41 & 27.80 & 0.396 \\
\hline Mean duration of ventilation (days) & 4.63 & 3.80 & 0.642 \\
\hline Mean length of ICU admission (days) & 6 & 5.80 & 0.931 \\
\hline Mean length of hospital stay (days) & 22.50 & 21.80 & 0.955 \\
\hline
\end{tabular}

Table 2: Mean of variables in favorable and unfavorable GOSE group

\begin{tabular}{l|l|c|c|c|}
\hline \multirow{3}{*}{ Age } & Category & N=21 & Mean GOSE & P value \\
\hline \multirow{3}{*}{ Sex } & Less than 50 years & 4 & 4.75 & 0.003 \\
& More than 50 years & 17 & 1.35 & 0.084 \\
\hline \multirow{2}{*}{ Timing of surgery } & Male & 15 & 2.53 & 0.67 \\
& Female & 6 & 2.24 & 0.333 \\
\hline \multirow{2}{*}{ Timing of surgery } & On arrival & 4 & 1 & 0.175 \\
& After deterioration & 16 & 2.38 & 0.80 \\
\hline \multirow{2}{*}{ Timing of surgery } & Less than 48 hours & 5 & 2.44 & 0.862 \\
\hline
\end{tabular}

Table 3: Mean GOSE among different categories of patients. 
Decompressive hemicraniectomy in malignant MCA infarct

\begin{tabular}{l|c|c|c}
\hline & Unfavorable GOSE & Favorable GOSE & Fisher's exact test \\
\hline Left side & 7 & 3 & P value: 0.525 \\
Right side & 9 & 2 & \\
\hline Total & $\mathbf{1 6}$ & $\mathbf{5}$ & \\
\hline
\end{tabular}

Table 4: Comparison of side of decompression with GOSE.

\section{Discussion}

In the era of thrombolysis and thrombectomy very few patients with stroke require DHC, usually the one with complete ICA block or MMCA infarct. ${ }^{5}$ Though it is well known fact that $\mathrm{DCH}$ is a lifesaving procedure, various studies have shown different functional outcome. ${ }^{6}$ It is seen that almost $10 \%$ of all ischemic stroke are massive enough to require decompressive hemicraniectomy, ${ }^{7}$

We are seeing more and more young patients with stroke, the youngest being 29 years of age. The epidemiological study done suggests increasing trend of stroke in young though overall incidence is decreasing. ${ }^{8.9}$ There was male preponderance reflecting on the established fact that male gender is an unmodifiable risk factor for ischemic stroke. ${ }^{10}$ The mean time of arrival was more than 48 hours as patients came from across the country and the transportation are mostly by road from outside the capital city. This might have an effect on the outcome in patients.

In our study, the mean age of patients with favorable outcomes was lower than those with unfavorable outcomes. We observed that a favorable outcome was seen among people of lower age ( $<50$ years). A meta-analysis of English and Chinese database showed survival among DHC in MMCA infarction increased among all age group whereas more disability was seen among age group of 60 and above. ${ }^{11}$ We dichotomized our data at 50 years because the mean age of unfavorable and favorable groups were 62 and 46 respectively.

Many studies show that early DCH (within 48 hours) has a favorable outcome. ${ }^{12}$ However, in this study, though mean GOSE was better with early DCH, it did not show statistical significance when we dichotomized the data at 48 hours and 24 hours of arrival for timing of surgery. But only single centre study showed better outcome when DCH was done before 24 hours. ${ }^{13}$

Preoperative GCS has been shown to predict outcome in some studies with favorable outcome at a cut-off of GCS 8 or more. ${ }^{14}$ This finding was not seen in our study. Though we see shorter ICU stay and shorter requirement of ventilation among the group with favorable outcomes, they did not achieve statistical significance in our study. Despite this mortality is high among patients requiring $\mathrm{DCH}$ in all age group. ${ }^{15}$ We had a mortality rate of $50 \%$ in our study. We also compared the outcome of decompressing left versus right sided malignant infarct but found no significant difference. This finding is similar to the study done at Oslo university. ${ }^{16}$

Though the side of the decompression was studied for outcome, proper documentation of dominance was not available for interpretation. Volumetric scan to quantify the amount of infarct could also be a factor to predict outcome of these patient. ${ }^{17}$ However we did not have such data so couldn't be studied. These studies are helpful in changing the perception of neurosurgeons and neurologist towards DCH in MMCA infarct. ${ }^{18}$

\section{Conclusion}

Patients with age less than 50 years have favorable GOSE despite MMCA infarction if decompressive hemicraniectomy is performed to accommodate brain swelling. Operating early at presentation rather than waiting for deterioration might improve the outcome.

\section{Conflict of Interest: None Source(s) of support: None}

\section{References}

1. Hofmeijer J, Kappelle LJ, Algra A, Amelink GJ, van Gijn J, van der Worp HB; HAMLET investigators. Surgical decompression for space-occupying cerebral infarction (the Hemicraniectomy After Middle Cerebral Artery infarction with Life-threatening Edema Trial [HAMLET]): A multicentre, open, randomised trial. Lancet Neurol. 2009;8(4):326-33. https://doi.org/10.1016/S1474-4422(09)70047-X

2. Vahedi K, Vicaut E, Mateo J, Kurtz A, Orabi $\mathrm{M}$, Guichard JP, et al; DECIMAL Investigators. Sequential-design, multicenter, randomized, controlled trial of early decompressive craniectomy in malignant middle cerebral artery infarction (DECIMAL Trial). Stroke. 2007;38(9):2506-17. https://doi.org/10.1161/STROKEAHA.107.485235

3. Jüttler E, Schwab S, Schmiedek P, Unterberg A, Hennerici M, Woitzik J, et al; DESTINY Study Group. Decompressive Surgery for the Treatment of Malignant Infarction of the Middle Cerebral Artery (DESTINY): A randomized, controlled trial. Stroke. 2007;38(9):2518-25. https://doi.org/10.1161/ STROKEAHA.107.485649 


\section{Koirala et al}

4. Frank JI, Schumm LP, Wroblewski K, Chyatte D, Rosengart AJ, Kordeck C, Thisted RA; HeADDFIRST Trialists. Hemicraniectomy and durotomy upon deterioration from infarction-related swelling trial: Randomized pilot clinical trial. Stroke. 2014;45(3):781-7. https://doi.org/10.1161/ STROKEAHA.113.003200

5. Rumalla K, Ottenhausen M, Kan P, Burkhardt JK. Recent nationwide impact of mechanical thrombectomy on decompressive hemicraniectomy for acute ischemic stroke. Stroke. 2019;50(8):2133-9. https://doi.org/10.1161/STROKEAHA.119.025063

6. Lin J, Frontera JA. Decompressive hemicraniectomy for large hemispheric strokes. Stroke. 2021;52(4):1500-10. https://doi.org/10.1161/ STROKEAHA.120.032359

7. Suyama K, Horie N, Hayashi K, Nagata I. Nationwide survey of decompressive hemicraniectomy for malignant middle cerebral artery infarction in Japan. World Neurosurg. 2014;82(6):1158-63. https://doi. org/10.1016/j.wneu.2014.07.015

8. Sultan S, Elkind MS. The growing problem of stroke among young adults. Curr Cardiol Rep. 2013 ;15(12):421. https://doi.org/10.1007/s11886-0130421-Z

9. Smajlović D. Strokes in young adults: Epidemiology and prevention. Vasc Health Risk Manag. 2015;11:157-64. https://doi.org/10.2147/VHRM. S53203

10. Choudhury MSJH, Choudhury MTI, Nayeem A, Jahan WA. Modifiable and non-modifiable risk factors of stroke: A review update. J Natl Inst Neurosci Bangladesh. 2015;1(1):22-6. https://doi. org/10.3329/jninb.v1i1.22944

11. Li YP, Hou MZ, Lu GY, Ciccone N, Wang XD, Dong L, et al. Neurologic functional outcomes of decompressive hemicraniectomy versus conventional treatment for malignant middle cerebral artery infarction: A systematic review and meta-analysis. World Neurosurg. 2017;99:709-25.e3. https://doi. org/10.1016/j.wneu.2016.12.069
12. Dasenbrock $\mathrm{HH}$, Robertson $\mathrm{FC}$, Vaitkevicius $\mathrm{H}$, Aziz-Sultan MA, Guttieres D, Dunn IF, et al. Timing of decompressive hemicraniectomy for stroke: A nationwide inpatient sample analysis. Stroke. 2017;48(3):704-11. https://doi.org/10.1161/ STROKEAHA.116.014727

13. Kilic M, Ertem DH, Ozdemir B. Timing of decompressive craniectomy for malignant middle cerebral artery infarction: A single-center analysis. Medicina (Kaunas). 2019;55(2):31. https://doi. org/10.3390/medicina55020031

14. Tsai CL, Chu H, Peng GS, Ma HI, Cheng CA, Hueng DY. Preoperative APACHE II and GCS scores as predictors of outcomes in patients with malignant MCA infarction after decompressive hemicraniectomy. Neurol India. 2012;60(6):608-12. https://doi.org/10.4103/0028-3886.105195

15. Walz B, Zimmermann C, Böttger S, Haberl RL. Prognosis of patients after hemicraniectomy in malignant middle cerebral artery infarction. J Neurol. 2002;249(9):1183-90. https://doi.org/10.1007/ s00415-002-0798-x

16. Sundseth J, Sundseth A, Thommessen B, Johnsen LG, Altmann M, Sorteberg W, et al. Long-term outcome and quality of life after craniectomy in speech-dominant swollen middle cerebral artery infarction. Neurocrit Care. 2015;22(1):6-14. https:// doi.org/10.1007/s12028-014-0056-y

17. Hecht N, Neugebauer H, Fiss I, Pinczolits A, Vajkoczy P, Jüttler E, et al. Infarct volume predicts outcome after decompressive hemicraniectomy for malignant hemispheric stroke. J Cereb Blood Flow Metab. 2018;38(6):1096-103. https://doi. org/10.1177/0271678X17718693

18. Basu P, Jenkins H, Tsang K, Vakharia VN. National survey of neurosurgeons and stroke physicians on decompressive hemicraniectomy for malignant middle cerebral artery infarction. World Neurosurg. 2017;102:320-8.https://doi.org/10.1016/j. wneu.2017.02.043 